Please note: This is a preprint of Adams, M. (2021) Critical psychologies and climate change. Current Opinion in Psychology. https://doi.org/10.1016/j.copsyc.2021.01.007 If citing, please refer to published version.

\title{
Critical psychologies and climate change
}

Matthew Adams ${ }^{1}$

\begin{abstract}
This article is a review of recent contributions in critical psychology, and its close cousins, critical social psychology, critical community psychology and liberation psychology, to understandings of the human response to climate change. It contrasts critical psychology with mainstream psychology in general terms, before introducing a critical psychological perspective on climate change. Central to this perspective is a critique of the framing of individual behaviour change as the problem and solution to climate change in mainstream psychology, and a related emphasis on identifying 'barriers' to pro-environmental behaviour. This framework is argued to be reductive, obscuring or downplaying the influence of a range of factors in shaping predominant responses to climate change to date, including social context, discourse, power and affect. Currently, critical psychologies set out to study the relative contribution of these factors to (in)action on climate change. A related concern is how the psychological and emotional impacts of climate change impact unevenly on communities and individuals, depending on place-based, economic, geographic and cultural differences, and giving rises to experiences of injustice, inequality and disempowerment. Critical psychology does not assume these to be overriding or inevitable psychological and social responses, however. Critical psychologies also undertake research and inform interventions that highlight the role of collective understanding, activism, empowerment and resistance as the necessary foundations of a genuine shift towards sustainable societies.
\end{abstract}

Keywords: climate change, psychology, critical, community, emotion, power, resistance, environmental justice

\footnotetext{
${ }^{1}$ Email: matthew.adams@brighton.ac.uk. Affiliation: University of Brighton, Falmer, Brighton, BN1 9PH
} 


\section{Critical Psychologies and Climate Change}

\section{Introduction}

Critical psychology offers a unique contribution to understanding the psychological dimensions of climate change. The core concerns of critical psychology include a fuller acknowledgement of the role of social context, interaction and emotional depth in shaping individual experience; the identification of forms of inequality, injustice and oppression, including those that the discipline of psychology has contributed to; and a commitment to social and political transformation reflected in democratic participation, empowerment and equality. These are concerns that have more recently lent themselves to a critical engagement with anthropogenic climate change and the contemporary sustainability agenda in psychology and the social sciences. Following a brief outline of critical psychology, its core concerns, and its differences from mainstream psychology, the main focus of this article is to provide an overview of recent work, mostly from 2019 onwards, developing a critical psychological perspective on climate change.

Critical psychology, and its close cousins, critical social psychology, critical community psychology and liberation psychology, are not really branches of psychology in the same sense as say health, social or educational psychology [1]. ${ }^{1}$ They are more like a loosely associated set of theoretical perspectives, methods and positions from which if viewed together, whilst varied in emphasis and sometimes at odds, the following shared tenets can pretty confidently be discerned. Foremostly critical psychologies are, unsurprisingly, defined by the adoption of a pervasively critical standpoint. Critique is directed towards the theories, methods and practices of Psychology as a discipline, the construction of psychological knowledge, and its role in supporting, maintaining or ignoring historical and existing social inequalities and injustices [2]. It is also more broadly committed to addressing the psychological dimensions of injustice and inequalities, developing psychological methods and practices to better understand and give voice to marginalised and oppressed peoples, within a critical and justice-oriented framework $[3,4]$.

In advancing this framework, critical psychologies advocate the development and application of alternative theories and methods. These alternatives are underpinned by a commitment to a psychology that 'stresses the social embeddedness of experience' [5], and a related concern with identifying the role of power relations in shaping psychological processes, maintaining inequality and oppression $[2,3,4]$. Although the relationship between psychodynamic and critical psychology is complex to say the least, a final area of emphasis on complex and contradictory emotional states, understood at times as both collective and unconscious, and their role in shaping behaviour and experience $[6,7]$.

In recent years, critical psychology has applied these tenets to the issue of climate change. The next sections offer an account of recent key theoretical, conceptual, empirical and applied developments that fall under the heading of critical psychologies 
of climate change. The themes addressed are social context and social change; ecoanxiety and ecological grief; discourse, language and social representations; power and resistance. Finally, I offer a brief reflection on the contribution of critical psychologies to understanding the psychological dimensions of climate change to date.

\section{Critical psychology \& climate change}

In recent years we have seen a rapid expansion in the application of psychology to climate change, environmental and sustainability issues, increasing the legitimacy and authority of the models of human behaviour it advances [8,9]. Today the theories and methods of mainstream psychology are commonly utilized to answer questions about how people's attitudes, values, motives and beliefs operate as variables that shape 'environmentally significant behaviour', especially in terms of 'barriers' to action on climate change and applied to interventions and policies aimed at encouraging proenvironmental or 'sustainable behaviour' and/or reducing 'unsustainable behaviour' $[10,11,12]$.

Whilst critical psychologies have been relatively slow to develop specific positions in relation to mainstream psychological approaches to the topic of climate change [13, 14], and to the development of alternative perspectives and agendas, this contribution to the Current Opinion in Psychology special issue offers a timely moment to take stock of new and recent research and scholarship. In what remains of this review, key elements of critical psychologies of climate change are sketched with reference to recent work, organised into the themes outlined above.

\subsection{Social context \& social change}

In placing so much emphasis on psychological 'barriers' as explanations for inaction on climate change, critical psychologies argue that the relevance of social situations, societal structures and more complex interpersonal dynamics are downplayed, if they appear as significant issues at all [15]. Recent critical psychologies have focused on mainstream psychology's contribution in this context as obscuring the structural, social and power relations that underpin and maintain the climate crisis $\left[16^{* *}\right]$, and therefore tacitly endorsing a problematic status quo. Mirroring a key tenet of critical psychologies, the alternative to this form of psychological reductionism is to more fully address how psychological processes are socially embedded, and how this embeddedness shapes climate-relevant (in)action $\left[17^{* *}, 18^{*}, 19^{* *}\right]$. Critical psychologies therefore pay theoretical and empirical attention to multiple, overlapping dimensions of social context, including the role of interpersonal and group dynamics, social rules, norms and networks, social representations, discourses and ideologies, the activities, policies and practices of government, large corporations and other institutions as well as the alliances between them $\left[14,20,21,22,23^{*}\right]$. Critical work relatedly emphasises the situated dynamics of disempowerment and empowerment $\left[16^{* *}, 24^{*}, 25^{* *}, 26\right]$, and the urgent need for societal change as well as an expanded understanding of behavioural change in addressing the climate crisis $\left[17^{* *}, 19^{* *}, 27^{*}\right]$. 
Critical psychologies do not suggest individuals are powerless in the face of social forces beyond their control [19**]. On the contrary, shifting the social and cultural conditions of existence conceptually from taken-for-granted and immutable backdrop for individual behaviour to powerful but dynamic forces means they can potentially be challenged and transformed $\left[16^{* *}, 24^{*}\right]$. Barnwell and colleagues' interviews with communities directly affected by the activities of extractive industries are a case in point [24*]. They highlight the significance of a mining community's shared psychological reactions to land and environmental injustices in Rustenburg, South Africa, conceptualising 'place severing' as a profoundly unsettling, embodied response. However, they also stress resistance as a common psychological and collective rejoinder emerging from shared experiences of loss, which have the potential to be 'unifying, mobilising and empowering for communities resisting ongoing extraction'.

To this end, critical psychology readily extends the definitions of 'environmentally significant behaviours' relevant to climate and ecological crisis, to include forms of environmental activism, protest and resistance, especially, but not exclusively, those resulting from attachments to place $\left[14,17^{* *}, 24^{*}\right]$. It seeks to understand the factors contributing to activist behaviour and their role in contributing to empowerment, political participation, social movements and social change $\left[27^{*}, 28,29,30,31,32^{*}, 33\right.$, 34]. A critical psychological position therefore questions a focus on motivating individual attitude and behaviour change within existing social and political structures, instead undertaking theory and research that recognises and challenges those prevailing structures $\left[13,14,17^{* *}\right]$.

\subsection{Affect \& emotion}

In recent work expanding critical understandings of the psychological processes involved $[35,36]$, we see a greater recognition of the deeper emotional, affective dimensions of psychologies of climate change $\left[37^{*}, 38,39\right]$. These extend to both direct and anticipatory fear and loss, including solastalgia and ecological/environmental grief, eco-anxiety, dread, despair, existential crisis, and trauma [40, 41*, 42**]; and relatedly, the emotional impacts of climate change and related phenomena such as extreme weather events on different groups and communities [28, 43*, 44, 49]. Randall and Hoggett's interviews with climate scientists and activists, for example, revealed distinct emotional terrains involving a fascinating and complex array of defences, support networks and interpersonal challenges [28].

Especially important here are accounts of how trauma and distress are distributed geographically and socially in uneven, unequal and unjust ways, with individuals and communities disproportionately bearing the brunt of the effects of anthropogenic climate change and ecological degradation in light of their relative contribution to the problem - a 'double injustice' $\left[45^{*}, 46,47\right]$. Ashlee Cunsolo and colleagues add to this burgeoning body of scholarship by focusing on the various forms of ecological loss and grief experienced by Inuit in Labrador, Canada [46]. Caribou herds, central to indigenous Inuit culture, sustenance and identity in these areas, have witnessed a rapid decline as a result of climate change and related factors. Inuit-led research 
utilising in-depth interviews reveals complex lived experiences of ecological grief and mourning in response to caribou population decline. This is an example of critical work empirically centring understandings of affect and emotion in terms of geography and power, whilst extending the conceptualisation of the complex emotional responses involved. There is now an important shift in critical work to recognise experiences of distress situated in place, not least those communities and places routinely ignored and denied a voice in relation to climate change $[48,49,50]$.

In mainstream psychological discourses there is a tendency to locate these kinds of experiences within a medical or quasi-medical framework $\left[25^{* *}, 51^{*}\right]$. Critical psychologies are resisting such a move, on the basis that it unhelpfully loosens those experiences of distress form their social, political and historical moorings, leaving them free-floating in a world of individual responsibilisation and adaptability $\left[13,17^{* *}, 18^{*}\right]$. Instead, critical work highlights how such experiences are grounded in accurate readings of reality $\left[5^{*}, 52\right]$. It also considers the shared, collective nature of affective experiences such as distress and the implications for localised responses to climate change, how communities are affected, and social action [4, 53]. Critical psychologies more generally argue for wider social and cultural acknowledgement of profound emotional responses. Recognising such responses is considered a basis for overcoming a tendency towards disavowing the realities of climate change [35, 52, 54*, 55], and therefore a vital foundation for social and political struggles $\left[24^{*}, 40,42^{* *}\right]$. Critical work therefore addresses how individuals, groups and communities can and do work with affective and emotional responses to co-operate, resist and challenge the detrimental effects of climate change and related environmental issues $\left[24^{*}, 27^{*}, 30\right.$, $\left.34,41^{*}\right]$.

\subsection{Discourse, language \& social representations}

A key theme in critically oriented psychology addressing climate change has been the role of language, discourse and social representations in shaping individual, interpersonal and collective understandings of and responses to climate change [13, 14]. Drawing on variations of content, conversation and discourse analysis, established methodological tools in critical psychologies, recent research foci have been interview data and 'everyday' conversations about climate change and environmental issues [20, $\left.23^{*}, 41,56,57\right]$; analysis of climate change denial discourses in online discussion forums and social media [55, 58]; and televisual and news-media representations of climate activism $[22,59]$. The implications of this work are varied, but all take engaging in discourse and social representations as a form of climate-relevant practice in its own right, meaningfully constructing and addressing environmental issues [23]. In addressing this complexity, understanding the 'barriers' to action on climate change as predominately individual is considered partial and reductive $\left[17^{* *}, 19^{* *}\right]$. This work makes a strong case for the argument that psychological understandings of, and responses to, climate change - from deep-seated denial to engaged activism - cannot be considered in isolation, but are embedded in interpersonal, community and wider cultural, social, political and material structures, all shot through with issues of power and resistance. 


\subsection{Power \& resistance}

From a critical psychological perspective, a focus on individual psychological barriers to climate-relevant action flattens the social plane to one of freely interacting agents ignoring or downplaying how power is used in particular ways by and on others $[13,14$, $\left.17^{* *}, 19^{* *}\right]$. As noted in relation to the themes above, critical psychologies conceptualise power at the heart of explanations of capacities for action in response to climate change $\left[24^{*}, 25^{* *}, 26,27,30\right]$, and an important focus is the experiences of people most adversely affected whilst simultaneously disempowered [45*]. This includes research emanating from high climate vulnerable regions with substantial indigenous populations, and countries and regions in the global South $[48,49]$. Researchers ask questions about who's voices are ignored and suppressed in understanding and responding to the climate crisis, asking 'how power is distributed, and why people in positions of power choose to use that power in particular ways' $\left[17^{* *}\right]$; as well as citing and researching voices of active resistance commonly marginalised $\left[16^{* *}, 24^{*}, 25^{* *}, 46,48,49,50\right]$.

The study of power in this context is emphatically not limited to vulnerable groups and communities as passively and chronically disempowered by climate change, but also the study of opportunities for empowerment - the processes 'by which marginalised communities are organizing, resisting, fighting and overcoming oppression in the face of climate change and environmental injustices' $\left[16^{* *}\right]$. In the process of undertaking psychological research, it is argued that community psychologists should explicitly seek ways to assist and accompany communities seeking to resist and remedy land, climate and environmental injustices [24*]. In this context, critical psychological methods and interventions are designed to support and enhance community attempts to overcome challenges and connect with the aforementioned interest in activism as a form of 'pro-environmental behaviour'.

\section{Conclusion}

The theories and methods of mainstream psychology have for some time been utilised to make sense of climate change, especially in relation to psychological adaptation, and factors involved in encouraging or discouraging 'pro-environmental behaviour' [8, 9, $10,11]$. Critical psychologies rightly challenge the vision of psychology as a progressive tool for modifying behaviour in terms of adapting to a changing climate in ways that protect physical and mental health, development, resilience; and for making choices that are more environmentally sustainable - e.g., conserving energy, opting for sustainable transport, recycling and so on. Critical psychologies question whether the kinds of change advanced here will add up to social transformation on a scale necessary to mitigate the ill-effect of climate change scenarios; they stress the injustice and inequalities often overlooked in established attempts to address climate change that target individual behaviour change and technological solutions [33].

That said, the dividing lines between critical and mainstream approaches to climate change are not clear cut. Whilst there is some doubling down on a 'psychological 
barriers' paradigm $\left[17^{* *}\right]$, there is also a growing convergence in terms of a mutual emphasis on behavioural and societal change [6o, 61]. Divisions remain however, with critical psychologies more readily advocating a recognition of environmental (in)justice, emotional complexity, power and elites, and the factors involved in facilitating activism. Advocates of critical psychologies, though relatively small in number and influence, remain at the forefront in pushing for the critical application of psychological knowledge and establishing alternative approaches, and increasingly, listening to and working with individuals and groups, including researchers, representative of the communities already deeply affected by anthropogenic climate change and ecological degradation. Most significantly perhaps, in the context of the urgency of the climate crisis, it is the persistent call for structural, societal and psychological transformation that sets critical psychologies apart.

\section{References and recommended reading}

Papers of particular interest, published within the period of review, have been highlighted as:

* of special interest

** of outstanding interest

[1] Holzman, L. Critical psychology, philosophy, and social therapy. Human Studies, 2013: 36[4], 471-489.

[2] Teo, T. Critical psychology: A geography of intellectual engagement and resistance. American Psychologist, 2013: 7o[3], 243-

254. https://doi.org/10.1037/a0038727

[3] Gough, B. Critical social psychologies: Mapping the terrain. In The Palgrave handbook of critical social psychology. London: Palgrave Macmillan, 2017, pp. 3-14.

[4] Kagan, C., Burton, M., Duckett, P., Lawthom, R., \& Siddiquee, A. Critical community psychology: Critical action and social change. London: Routledge, 2019.

[5] Gough, B., \& Macfadden, M. Critical Social Psychology: An Introduction. Basingstoke: Palgrave, 2001.

[6] Caputo, A., \& Tomai, M. A systematic review of psychodynamic theories in community psychology: Discovering the unconscious in community work. Journal of Community Psychology, 2020, 48[6], 2069-2085.

[7] Mikkelsen, E. N., Gray, B., \& Petersen, A. Unconscious processes of organizing: Intergroup conflict in mental health care, 2020. Journal of Management Studies.

[8] Nielsen, K. S., Clayton, S., Stern, P. C., Dietz, T., Capstick, S., \& Whitmarsh, L. How psychology can help limit climate change, 2020. American Psychologist.

[9] Reser, J. P., \& Swim, J. K. Adapting to and coping with the threat and impacts of climate change. American Psychologist, 2011, 66[4], 277.

[10] Gifford, R. The dragons of inaction: psychological barriers that limit climate change mitigation and adaptation. American psychologist, 2011, 66 [4], 290.

[11 Swim, J.K., Stern, P.C., Doherty, T.J., Clayton, S., Reser, J.P., Weber, E.U., Gifford, R. and Howard, G.S. Psychology's contributions to understanding and addressing global climate change. American psychologist, 2001: 66[4], p.241.

[12] Lange, F., \& Dewitte, S. Measuring pro-environmental behavior: Review and recommendations. Journal of Environmental Psychology, 2019: 63, 92-100. 
[13] Adams, M. Environment: Critical social psychology in the Anthropocene. In B. Gough [ed.] Handbook of Critical Social Psychology. London: Palgrave Macmillan. Pages 621-641, 2017.

[14] Adams, M. Approaching nature, 'sustainability' and ecological crises from a critical social psychological perspective. Social and Personality Psychology Compass, 2014: 8, 251-262.

[15] Dreyer, B., \& Riemer, M. Community and participatory approaches to the environment. In K. O’Doherty \& D. Hodgetts [Eds.], Handbook of Applied social Psychology. London: Sage Publications, 2018.

[16] ${ }^{* *}$ Fernandes-Jesus, M., Barnes, B., \& Diniz, R. F. Communities reclaiming power and social justice in the face of climate change. Community Psychology in Global Perspective, 2020: 6[2/2], 1-21.

This paper is an introduction to a special issue in Community Psychology in Global Perspective containing articles rooted in critical community psychology perspectives. It provides an important foundation for a research and intervention agenda for a critical community psychology of climate change, emphasising issues of power, inequality and well-being in communities' struggles for climate and environmental justice across the globe, especially marginalised communities and countries in the global South.

${ }_{[17]}^{* * S c h m i t t, ~ M . ~ T ., ~ N e u f e l d, ~ S . ~ D ., ~ M a c k a y, ~ C . ~ M ., ~ \& ~ D y s-S t e e n b e r g e n, ~ O . ~ T h e ~ p e r i l s ~ o f ~}$ explaining climate inaction in terms of psychological barriers. Journal of Social Issues, 2020: 76[1], 123-135.

A vital critical resource, this article adopts a critical social psychology approach to critique predominant 'psychological barriers explanation' [PBE] of inaction in response to climate change as partial and reductive. The authors explore the complex interplay between psychological processes, social relations, and social structures and call for psychologists to address existing power relations and explore possibilities for transformative social change.

[18] *Schill, C., Anderies, J.M., Lindahl, T., Folke, C., Polasky, S., Cárdenas, J.C., Crépin, A.S., Janssen, M.A., Norberg, J. and Schlüter, M. A more dynamic understanding of human behaviour for the Anthropocene. Nature Sustainability, 2019, 2, pp.10751082 .

The authors are critical of models of human behaviour in psychologies of climate change as overly static and atomised, advancing a 'complex adaptive systems approach' as an alternative. This approach is claimed to better represent the relationships between individual behaviour and socio-cultural-biophysical context, necessary for environmental governance in an age of profound climate crisis.

[19] **Räthzel, N., \& Uzzell, D. Critical Psychology -'Kritische Psychologie’: Challenging environmental behavior change strategies. Annual Review of Critical psychology, 2019: 16, 1375-1413. 
In this essential paper, the authors draw on the German version of critical psychology, Kritische Psychologie [KP]. They make an ambitious case for learning from KP's understanding of human beings, arguing that its model of the individual as the totality of their social relations is the basis for understanding and advocating genuinely transformative behaviour change strategies.

[2o] Hanna, P., \& Adams, M. Positive self-representations, sustainability and socially organised denial in UK tourists: discursive barriers to a sustainable transport future. Journal of Sustainable Tourism, 2019: 27[2], 189-206.

[21] Batel, S., \& Devine-Wright, P. Using NIMBY rhetoric as a political resource to negotiate responses to local energy infrastructure: a power line case study. Local Environment, 2020: 25[5], 338-350.

[22] Horsbøl, A. Green conflicts in environmental discourse. A topos based integrative analysis of critical voices. Critical Discourse Studies, 2020: 17 [4], 429446.

[23] * Nash, N., Whitmarsh, L., Capstick, S., Gouveia, V., Araújo, R.D.C.R., Dos Santos, M., Palakatsela, R., Liu, Y., Harder, M.K. and Wang, X. Local climate change cultures: climate-relevant discursive practices in three emerging economies. Climatic Change, 2019: 163(1), pp.63-82.

This paper reflects shift towards understanding climate change as a sociocultural phenomenon, and grounds climate-relevant psychological processes in wider cultural, political and material contexts. This is approached empirically through an analysis of people's lifestyle narratives in three culturally diverse emerging economies: Brazil, South Africa and China.

[24] *Barnwell, G. C., Stroud, L., \& Watson, M. "Nothing green can grow without being on the land": Mine-affected communities' psychological experiences of ecological degradation and resistance in Rustenburg, South Africa. Community Psychology in Global Perspective, 2020: 6[2/2], 87-109.

An important paper introducing concept of 'place severing' - 'the psychological process associated with harms done to place attachment, including to ancestral land, the unsettling of traditional knowledge systems, intergenerational identity processes and ancestral relationships, stemming from historical land and ecological injustices' (p. 89). The authors locate the psychological experiences of ecological degradation within communities, whilst also finding that grassroots organizing groups have key role in promoting community mobilisation, critical thinking, building alliances and empowering communities.

[25] ** Barnwell, G., Stroud, L., \& Watson, M. Critical Reflections from South Africa: using the Power Threat Meaning Framework to Place Climate-Related Distress in its Socio-Political Context. British Psychology Society: Clinical Psychology Forum Special Issue: Psychology and the Climate and Environmental Crisis, 2020: 332, pp. 7-15.

An essential contribution to a critical psychological approach. Possibly the first to apply the Power Threat Meaning Framework [PTMF] [an important critical 
development in clinical psychology] to climate-related distress. The paper utilises this model to critique medicalisation and dehistorisation in current conceptualisations of climate-related distress and highlight the importance of asymmetrical power dynamics.

[26] Askland, H. H. and Bunn, M. Lived experiences of environmental change: Solastalgia, power and place. Emotion, Space and Society, 2018: 27, 16-22.

${ }_{[27]}^{*}$ Reimer, M., Reich, S.R., Evans, S.D., Nelson, G, Prilleltensky, I. Community Psychology: Research and Action for Social Change and Wellbeing. In Community Psychology [3rd Edition]. In Pursuit of Liberation and Well-Being. London: Macmillan, pp. 3-28, 2020.

Helpful introductory overview of the value of a critically informed community psychology approach to environmental sustainability, focusing on problem definition, guiding principles, levels of analysis and types of research.

[28] Hoggett, P. and Randall, R. Engaging with Climate Change: Comparing the Cultures of Science and Activism. In P. Hoggett [Ed.] Climate Psychology: On Indifference to Disaster. Basingstoke: Palgrave pp. 239-262, 2019.

[29] Schmitt, M.T.,Mackay,C.M.L., Droogendyk, L. M. \& Payne,D. What predicts environmental activism? The roles of identification with nature and politicized environmental identity. Journal of Environmental Psychology, 2019: 61, 20-29.

[30] Trott, C. D., Rockett, M. L., Gray, E. S., Lam, S., Even, T. L., \& Frame, S. M. "Another Haiti starting from the youth": Integrating the arts and sciences for empowering youth climate justice action in Jacmel, Haiti. Community Psychology in Global Perspective, 2020: 6[2/2], 48-70.

[31] Francescato, D. Why we need to build a planetary sense of community. Community Psychology in Global Perspective, 2020: 6[2/2], 140-164.

[32] *Kurz, T., Prosser, A. M. B., Rabinovich, A., \& O’Neill, S. Could vegans and lycra cyclists be bad for the planet? Theorising the role of Moralised Minority Practice Identities in processes of societal-level change. Journal of Social Issues, 2020: 76, 86-100.

This theorisation of moralized minority practice identities [MMPIs] makes an interesting counter-intuitive contention - 'strong identification with "green practice" groups may hamper, rather than facilitate, societal-level shifts toward sustainability'. Potential implications for understandings of antecedents of pro-environmental identities and activism.

[33] Unanue, I., Patel, S. G., Tormala, T. T., Trott, C. D., Piazza Rodríguez, A. A., Méndez Serrano, K., \& Brown, L. M. Seeing more clearly: Communities transforming towards justice in post-hurricane Puerto Rico. Community Psychology in Global Perspective, 2020: 6[2/2], 22-47.

[34] Knight, K. Climate activism as a clinical psychologist. Counselling Psychology Review, August 2020: 332, pp. 40-44.

[35] Randall, R. Loss and climate change: The cost of parallel narratives. Ecopsychology, 2009, 1[3], 118-129. 
[36] Willox, A. C. Climate change as the work of mourning. Ethics $\mathcal{E}$ the Environment, 2012: 17[2], 137-164.

[37] *Wardell, S. Naming and framing ecological distress. Medicine Anthropology Theory, 2020: 7[2], pp. 187-201.

An overview of how ecological distress is defined and categorised in sample of popular discourse [online articles, blogs, and videos] in conjunction with recent academic literature. Subsequent discussion of the meaning-making processes involved emphasise the individual, institutional, and political dimensions of ecological distress.

[38] Usher, K., Durkin, J., \& Bhullar, N. Eco-anxiety: How thinking about climate change-related environmental decline is affecting our mental

health. International Journal of Mental Health Nursing, 2019: 28(6), pp. 1233-1234.

[39] Cunsolo, A., \& Ellis, N. R. Ecological grief as a mental health response to climate change-related loss. Nature Climate Change, 2018: 8[4], pp. 275-281.

[40] Woodbury, Z. Climate trauma: Toward a new taxonomy of trauma. Ecopsychology, 2019: 11 [1], 1-18.

[41] *Panu, P. Anxiety and the Ecological Crisis: An Analysis of Eco-Anxiety and Climate Anxiety. Sustainability, 2020: 12[19], 7836.

This paper offers a helpful overview of current theory, research and commentary exploring 'eco-anxiety' and 'climate anxiety' and related terms. It is of special importance for critical psychological perspective as it locates psychological understandings these terms within work addressing social and structural aspects and considers how and when eco-anxiety might be a basis for practical action.

[42] ${ }^{* *}$ Clayton, S. Climate anxiety: Psychological responses to climate change. Journal of Anxiety Disorders, 2020: 74, 102263.

A comprehensive overview of recent scholarship examining the possible effects of climate change on emotional and mental health. Addresses climate anxiety as a clinical issue whilst making a distinction between adaptive and maladaptive levels of anxiety, and warning against an emphasis on individual mental health at the expense of the societal response the author considers necessary to address climate change.

[43] Head, L., \& Harada, T. Keeping the heart a long way from the brain: The emotional labour of climate scientists. Emotion, Space and Society, 2017: 24, 34-41.

[44] *Westoby, R., \& McNamara, K. E. Fear, grief, hope and action. Nature Climate Change, 2019: 9[7], 500-501.

Reflecting on tourism research, the authors contribute to the argument that experiences of loss and grief in relation to cherished places might have a role to play in facilitating collective action.

[45] ${ }^{*}$ Galway, L. P., Beery, T., Jones-Casey, K., \& Tasala, K. Mapping the solastalgia literature: A scoping review study. International journal of environmental research and public health, 2019, 16[15], 2662. 
The authors examine power/powerlessness as a mediating factor of solastalgic experiences. They argue that power is an under-investigated dimension of place-based experiences of environmental degradation and loss. Social position, access to resources, and decision-making power are claimed to be contributing factors to the likelihood of experiencing solastalgia and its intensity.

[46] Cunsolo, A., Borish, D., Harper, S. L., Snook, J., Shiwak, I., Wood, M., \& Herd Caribou Project Steering Committee. "You can never replace the caribou": Inuit experiences of ecological grief from caribou declines. American Imago, 2020: 77[1], 31-59.

[47] Middleton, J., Cunsolo, A., Jones-Bitton, A., Wright, C. J., \& Harper, S. L. Indigenous mental health in a changing climate: a systematic scoping review of the global literature. Environmental Research Letters, 2020: 15[5], 053001.

[48] Middleton, J., Cunsolo, A., Jones-Bitton, A., Shiwak, I., Wood, M., Pollock, N., Flowers, C. and Harper, S.L. "We're people of the snow:" Weather, climate change, and Inuit mental wellness. Social Science E Medicine, 2020: 262, p.113137.

[49] Tschakert, P., Ellis, N. R., Anderson, C., Kelly, A., \& Obeng, J. One thousand ways to experience loss: A systematic analysis of climate-related intangible harm from around the world. Global Environmental Change, 2019: 55, 58-72.

[50] Farias, T. M., \& Pinheiro, J. Q. "This energy is clean, but here, on the dunes, it would be dirty": Renewable sources of energy and socio-environmental conflicts in Galinhos-RN, Brazil. Community Psychology in Global Perspective, 2020: 6[2/2], 110-124.

[51] *Bednarek, S. Is there a therapy for climate-change anxiety? Therapy Today, 2019: June, 36-39.

This paper represents an important critical perspective on eco- and climate anxiety, in that it argues against the medicalisation and dehistoricisation of the forms of distress these terms represent, calling instead for their recognition as necessary, understandable responses to the reality of the threat posed by anthropogenic climate change and the need for a collective response.

[52] Gibson, P. R. Waking up to the environmental crises. Ecopsychology, 2019: 11[2], 6777 .

[53] Watson, M. F., Bacigalupe, G., Daneshpour, M., Han, W. J., \& Parra-Cardona, R. COVID-19 interconnectedness: Health inequity, the climate crisis, and collective trauma. Family Process, 2020: 59[3], 832-846.

[54] *Hoggett, P. (Ed.) Climate Psychology: On Indifference to Disaster. Basingstoke: Palgrave. 2019

This edited collection focuses on (in)action in the face of climate change as complex combinations of emotional, ethical, social, organizational and cultural dynamics. It brings together recent perspectives, novel methodologies and findings drawing on critical psychological, psychoanalytic and psycho-social traditions. 
[55] Cagle, L. E., \& Herndl, C. Shades of denialism: discovering possibilities for a more nuanced deliberation about climate change in online discussion

forums. Communication Design Quarterly Review, 2019: 7[1], 22-39.

[56] Becker, S., \& Sparks, P. Talking about climate change mitigation: people's views on different levels of action. Sustainability, 2018: 10[5], 1357.

[57] Becker, S., \& Sparks, P. "It never rains in California": Constructions of drought as a natural and social phenomenon. Weather and Climate Extremes, 2020: 29, 100257.

[58] Roxburgh, N., Guan, D., Shin, K. J., Rand, W., Managi, S., Lovelace, R., \& Meng, J.

Characterising climate change discourse on social media during extreme weather events. Global environmental change, 2019: 54, 50-60.

[59] Rafaely, D., \& Barnes, B. African climate activism, media and the denial of racism: The tacit silencing of Vanessa Nakate. Community Psychology in Global Perspective, 2020: 6[2/2], 71-86.

[6o] Carmichael, R. Behaviour change, public engagement and Net Zero. A report for the Committee on Climate Change. Retrieved from https://www.theccc.org.uk/publications/ 2019.

[61] Carmichael, R., \& Wainwright, T. Psychology and the road to Net Zero. Clinical Psychology Forum, August 2020: 332, pp.70-73.

\footnotetext{
${ }^{1}$ Hence the reference to critical psychologies plural in the rest of this article unless otherwise specified.
} 